\title{
Psychological well-being and psychological distress: is it necessary to measure both?
}

\author{
Helen R Winefield ${ }^{1 *}$, Tiffany K Gill ${ }^{2}$, Anne W Taylor ${ }^{2}$ and Rhiannon M Pilkington ${ }^{2}$
}

\author{
* Correspondence: helen.winefield@ \\ adelaide.edu.au \\ ${ }^{1}$ School of Psychology \& Discipline \\ of Psychiatry, University of Adelaide, \\ Adelaide, South Australia 5005, \\ Australia \\ Full list of author information is \\ available at the end of the article
}

\begin{abstract}
Background: The objectives of the study were to explore a self-report measure for psychological well-being and to investigate the relationship between psychological well-being and psychological distress.

Method: Telephone interviews of a representative sample of adults $(N=1933)$ collected information about sociodemographic variables, a standardised measure of psychological distress, and three brief existing scales to assess aspects of psychological well-being: Positive Relations with Others, Environmental Mastery, and Satisfaction with Life. The total of these three scales was also computed and explored as a measure of overall well-being.

Results: Variables positively associated with psychological well-being were negatively associated with psychological distress and vice versa. For example low psychological well-being and high psychological distress were associated with being the only adult in the household, speaking a language other than English at home, being divorced or separated, having no educational qualifications beyond secondary school, being unable to work, having a low income, renting one's accommodation, and receiving a pension.

Conclusions: The measure of well-being shows psychometric promise for community surveys. Psychological well-being is not exactly the opposite end of the continuum to psychological distress, but more debate is needed about whether and when, research participants need to be asked questions about both.
\end{abstract}

Keywords: Psychological well-being, Measurement, Life satisfaction, Psychological distress

\section{Background}

The positive psychology movement and corresponding social capital/new economics perspectives in public health, exemplified by the Foresight Mental Capital and Wellbeing Project (2008), draw attention to the desirability of developing reliable and valid standardised scales to measure psychological well-being (PW). As summarised in the WHO report (Freidli 2009, p.2): "a growing number of longitudinal studies confirm their [i.e. well-being scales] power to predict outcomes, for example, longevity, physical health, quality of life, criminality, drug and alcohol use, employment, earnings and pro-social behaviour (e.g. volunteering)". In much the same way that we have accepted the need to measure physical health and well-being rather than being restricted to

\section{Springer}

(c) 2012 Winefield et al.; licensee Springer. This is an Open Access article distributed under the terms of the Creative Commons Attribution License (http://creativecommons.org/licenses/by/2.0), which permits unrestricted use, distribution, and reproduction in any medium, provided the original work is properly cited. 
measures of illness and dysfunction, we need psychometrically sound assessment tools for psychological well-being. Unless these two attributes are perfectly negatively correlated - just opposite ends of the same continuum - attending only to distress risks leaves important gaps in our understanding of health, well-being, quality of life and resilience. This paper reports an apparently useful measure of PW and takes the opportunity in a large representative sample of adults, to contribute to the debate around the bipolar or bivariate nature of PW and psychological distress or dysfunction (PD).

Psychological well-being is usually conceptualised as some combination of positive affective states such as happiness (the hedonic perspective) and functioning with optimal effectiveness in individual and social life (the eudaimonic perspective) (Deci \& Ryan 2008). As summarised by Huppert (2009, p.137): "Psychological well-being is about lives going well. It is the combination of feeling good and functioning effectively." By definition therefore, people with high PW report feeling happy, capable, wellsupported, satisfied with life, and so on; Huppert's (2009) review also claims the consequences of PW to include better physical health, mediated possibly by brain activation patterns, neurochemical effects and genetic factors. Data in this area are necessarily correlational rather than experimental, but a report highlighting the value of assessing positive emotional states is that by $\mathrm{Xu}$ and Roberts (2010), using longitudinal data (1965 to 1993) from the Alameda County Study $(\mathrm{N}=6856)$. After controlling for age, sex, education, baseline health and social networks, longevity was predicted by positive emotions but not by negative. The effect held for both younger and older age-groups and was particularly clear for healthy adults. The authors called for more focus on positive emotions as a potential promoting agent for population longevity and health. Boehm et al. (2011) report similarly, based on a 5-year follow-up of 7942 participants in the Whitehall II cohort, an association between psychological well-being and a modest but consistent reduction in risk of incident CHD.

Measurement of psychological well-being utilises various instruments without any having gained dominance as a "gold standard". Life satisfaction is often a component (Diener et al. 1985; Diener et al. 2000; Diener et al. 2003; Lucas et al. 1996). Ryff's PW scales (Ryff 1989; Ryff and Singer 1996) offer a richer, multidimensional view including Autonomy, Environmental Mastery, Personal Growth, Positive Relations with Others, Purpose in Life, and Self-Acceptance. The 14-item Warwick-Edinburgh Mental Well-being Scale (Tennant et al. 2007) offers promise at the population level but its sensitivity to change requires more study. Keyes and colleagues' Mental Health Continuum-Short Form scale of 14 items (MHC-SF: Keyes 2005; Keyes et al. 2008; Lamers et al. 2011) has been developed from large South African and Dutch samples and extensively factor analysed as evidence of separate continua for mental illness and mental health. The measures used by Xu and Roberts (2010) were based on factor analyses of the Alameda County Study baseline psychological items (Berkman and Breslow 1983). These were: global life satisfaction (3 items), satisfaction with important life domains (your job, your marriage, your children), and positive affect (3 items). Boehm et al. (2011) used five items from disparate sources measuring "emotional vitality" plus one assessing optimism. The convergence of results using related but various measuring instruments can be seen as a sign of the robustness of these findings.

While philosophical and psychological theories abound concerning the nature of happiness and a good life, a question likely to interest epidemiologists is the relationship 
between this experiential state and, on the one hand various socio-demographic predictors, and on the other, objective and subjective health outcomes. There is a longstanding acceptance that psychological distress (PD) in the form of anxiety, sadness, irritability, self-consciousness and emotional vulnerability is strongly correlated with physical morbidity, reduced quality and duration of life, and increased use of health services (e.g. Lahey 2009). But what if anything does measurement of psychological well-being (PW) add to public health surveys? Are these concepts (PD and PW) sufficiently different to justify adding to respondent burden by measuring both, or will one suffice for at least some research purposes?

In order to examine the relationship between $\mathrm{PW}$ and $\mathrm{PD}$, we surveyed a community sample using a well-accepted screening test for PD, and also tested the psychometric properties of a PW scale using 16 questions about positive emotions. The latter included life satisfaction, sense of control and satisfying social relationships. The aims of the present study were:

1. To assess the psychometric properties (reliability and validity) of a collection of questions relevant to psychological well-being (PW), particularly the Diener Satisfaction with Life Scale (SWLS: Diener et al. 1985) and two of the Ryff Psychological Wellbeing scales (Environmental Mastery and Personal Relations);

2. To apply findings from the above to examine the demographic correlates of PW;

3. To examine relationships between PW and PD measured using the widelyused screening measure, the K10 (ABS 2001; Kessler et al. 2002). This was done in two ways, firstly by looking at the correlations between scores on the two sorts of measure, and secondly by examining whether predictors of the PW and PD are opposite ends of the same variables. If PD and PW are just mirror reflections of each other, high levels of factors associated with high PD might predict low PW and vice versa. On the other hand if PD and PW are independent (albeit overlapping) constructs they might be associated with different predictor variables.

\section{Methods}

\section{Participants}

All households in South Australia with a telephone connected and the telephone number listed in the Electronic White Pages were eligible for selection in the sample. Telephone numbers were selected randomly from the metropolitan and country areas. Only one interview was conducted per household. Where more than one person aged 18 or over resided in the household, the respondent was the person who was last to have their birthday. There were no replacements for non-contactable persons. A sample of 4500 was drawn of which 3325 households were eligible, losses occurring due to fax/ modem connections $(n=48)$, automated message or number not connected $(n=994)$, non-residential numbers $(\mathrm{n}=113)$ and deceased or otherwise ineligible $(\mathrm{n}=18)$. From the eligible sample of 3325, completed interviews were conducted with 1933 persons (58.1\%), nonparticipation being due to refusals $(\mathrm{n}=812)$, noncontact after 10 attempts $(\mathrm{n}=279)$, incapacitated $(\mathrm{n}=135)$, respondent unavailable $(\mathrm{n}=91)$, foreign language $(n=66)$, or interview terminated $(n=9)$. 


\section{Measures}

Respondents provided information about their sex, age group, the number of adults in the household and the number of children aged under 18 years, metropolitan or rural residence, country of birth and aboriginality, language spoken at home (English or other), marital status, education, work status, gross household income, and ownership or not of their dwelling. Psychological well-being was measured using the Diener Satisfaction with Life Scale (SWLS: Diener et al. 1985), comprising five items which require respondent to indicate to what extent they agree or disagree with the statement on a seven point likert type scale with higher scores corresponding to higher life satisfaction. An example item is "In most ways my life is close to my ideal". In addition we used two subscales from the Ryff Psychological Wellbeing Inventory (Ryff 1989). These were environmental mastery (EM: 5 items) and positive (social) relations (PR: 6 items). These subscales were chosen to reflect the sense of control and the supportive social relationships which have been consistently identified as integral aspects of psychological wellbeing. Environmental Mastery (EM) reflects the sense of power, control and autonomy widely accepted to have stress-reducing effects (Beck 2007), and positive Personal Relations (PR) with others have similar credence as facilitatory influences on health and wellbeing. Holt-Lunstad et al. (2010) showed the significant health benefits of social support in a large recent meta-analysis, while Cohen and Lemay (2007) have convincingly described the possible mechanisms of positive effects of social support. Response categories were on a five point scale ranging from "Strongly agree" to "Strongly disagree". Both dimensions were measured with positively and negatively worded items, with reverse coding so that higher scores indicated higher levels of psychological wellbeing. An EM item is "I'm good at managing my many daily responsibilities" and a PR item is "I often feel lonely because I have few close friends". The value of combining these concepts into one scale was explored by summing the scores of these three measures and conducting a factor analysis of the resultant 16 items here referred to as an Overall well-being scale.

Psychological distress was measured using the 10-item screening scale K10, as used in national and state-wide surveys in Australia (ABS 2001; Kessler et al. 2002). The items are based on the level of anxiety and depressive symptoms experienced in the most recent four-week period, for example: "how often did you feel nervous" and "how often did you feel hopeless". Subjects report the frequency of each experience on a five point scale ranging from 'all of the time' to 'none of the time'. The scoring system used is based on the method developed by the Clinical Research Unit for Anxiety and Depression at the University of New South Wales. In this method, five points are given for 'all of the time' to one point for 'none' of the time. This results in individual K10 scores being restricted to a range of 10-50.

\section{Procedure}

This survey obtained ethics approval from the SA Health Human Research Ethics Committee and the University of Adelaide Human Research Ethics Committee. A letter introducing the study was sent to the household of each selected telephone number. The letter informed people of the purpose of the survey and indicated that they could expect a telephone call within a defined time frame. Before the conduct of the main 
survey, the questionnaire was pilot tested $(\mathrm{n}=50)$ and where appropriate, wording was amended slightly.

To correct for disproportionality of the sample with respect to the population of interest, data were weighted by age, sex and area of residence to reflect the structure of the population in South Australia aged 18 years and over and probability of selection in the household (ABS 2007). The probability of selection was calculated based on the number of adults in the household and the number of telephone number listings for that household. Frequencies of demographic and social characteristics were determined as were the mean scores of each of the measurement scales. Internal reliability was determined using Cronbach's alpha and Pearson correlations determined the direction and strength of the linear association between the scales. Finally, mean scores for each demographic characteristic were determined. Significant differences were assessed using T-tests and one-way ANOVA were used to test for significant differences between groups with all post hoc comparisons conducted using the Scheffe test. Data were analysed using SPSS Version 15.0 and the conventional five per cent level of statistical significance was used.

Below we present descriptive results followed by correlations between the different scales used and comparisons of scores by sociodemographic variables. With the goal of investigating a potential composite measure of PW, scores from the three PW tests above were added and the resultant "Overall well-being" totals subjected to factor analysis.

\section{Results}

Demographic and social characteristics of the respondent sample are shown in Table 1. Respondents comprised approximately even numbers of men and women, welldistributed across age-groups and education and income categories and raw test scores on the measures of PW and PD in Table 2.

Each scale had acceptable internal reliability and the well-being scales were positively correlated with each other and negatively with distress, as expected. Variances accounted for ranged from 18.5\% (PR with K10), to 81\% (SWLS with Overall wellbeing). The composite measure consisting of the total of scores for the two Ryff scales and the Diener SWLS scale had a similar correlation with the K10 as did the component scales.

A principal components analysis (PCA) was conducted on the sixteen items that formed the Overall well-being score. Enough of the bivariate correlations were higher than 0.30 therefore it was considered appropriate to proceed with PCA. The KaiserMeyer-Olkin measure of sampling adequacy $(\mathrm{KMO}=0.912)$ was greater than 0.6 and Bartlett's Test of Sphericity was significant $\left(\chi^{2}=9187.01, p<.001\right)$ (Manning and Munro 2007). Communalities ranged from 0.292 (item 5, satisfaction with life scale "If I could live my life over I would change almost nothing) to 0.669 (item 2, satisfaction with life scale - "I am satisfied with life"). There was only one variable below 0.30 (at 0.29) suggesting that a good solution is likely.

Three components were extracted with eigenvalues greater than 1 , accounting in total for $51.39 \%$ of the total variance. Component 1 accounted for $24.9 \%$ of the variance. Item 1 (Q3 Diener scale), “Am satisfied with life", item 2 (Q1 Diener scale) "Life 
Table 1 Demographic and social characteristics of respondents $(N=1933)$

\begin{tabular}{|c|c|c|c|}
\hline Variable & Response categories & $\mathrm{n}$ & $\%$ \\
\hline \multirow[t]{2}{*}{ Sex } & Male & 939 & 48.6 \\
\hline & Female & 994 & 51.4 \\
\hline \multirow[t]{7}{*}{ Age group } & 18 to 24 years & 230 & 11.9 \\
\hline & 25 to 34 years & 306 & 15.8 \\
\hline & 35 to 44 years & 361 & 18.7 \\
\hline & 45 to 54 years & 358 & 18.5 \\
\hline & 55 to 64 years & 293 & 15.2 \\
\hline & 65 to 74 years & 190 & 9.8 \\
\hline & 75 years and over & 195 & 10.1 \\
\hline \multirow[t]{3}{*}{ Household size (adults) } & 1 adult & 294 & 15.2 \\
\hline & 2 adults & 1131 & 58.5 \\
\hline & 3 or more adults & 508 & 26.3 \\
\hline \multirow[t]{2}{*}{ Area of residence } & Metropolitan & 1425 & 73.7 \\
\hline & Country & 508 & 26.3 \\
\hline \multirow{5}{*}{$\begin{array}{l}\text { Number of children in } \\
\text { household (under } 18 \text { years) }\end{array}$} & None & 1208 & 62.5 \\
\hline & 1 child & 254 & 13.2 \\
\hline & 2 children & 310 & 16.0 \\
\hline & 3 or more children & 160 & 8.3 \\
\hline & Not stated & 1 & - \\
\hline \multirow[t]{3}{*}{ Country of birth } & Australia & 1499 & 77.5 \\
\hline & UK/reland & 195 & 10.1 \\
\hline & Other & 239 & 12.5 \\
\hline \multirow[t]{2}{*}{ Main language spoken at home } & English & 1852 & 95.8 \\
\hline & Other & 81 & 4.2 \\
\hline \multirow[t]{5}{*}{ Marital status } & Married/de facto & 1291 & 66.8 \\
\hline & Separated/divorced & 148 & 7.7 \\
\hline & Widowed & 118 & 6.1 \\
\hline & Never married & 375 & 19.4 \\
\hline & Refused & 1 & - \\
\hline \multirow{3}{*}{$\begin{array}{l}\text { Highest educational } \\
\text { qualification obtained }\end{array}$} & Secondary schooling & 889 & 46.0 \\
\hline & Trade/Certificate/Diploma & 618 & 32.0 \\
\hline & Bachelor degree or higher & 425 & 22.0 \\
\hline \multirow[t]{9}{*}{ Work status } & Full time employed & 754 & 39.0 \\
\hline & Part time/casual employment & 447 & 23.1 \\
\hline & Unemployed & 42 & 2.1 \\
\hline & Home duties & 121 & 6.2 \\
\hline & Retired & 420 & 21.7 \\
\hline & Student & 58 & 3.0 \\
\hline & $\begin{array}{l}\text { Unable to work because of } \\
\text { disability/Workcover/invalid }\end{array}$ & 62 & 3.2 \\
\hline & Other & 24 & 1.2 \\
\hline & Refused & 5 & 0.3 \\
\hline \multirow[t]{2}{*}{ Gross annual household income } & Up to $\$ 20,000$ & 244 & 12.6 \\
\hline & $\$ 20,000$ to $\$ 40,000$ & 310 & 16.0 \\
\hline
\end{tabular}


Table 1 Demographic and social characteristics of respondents $(\mathbf{N}=1933)$ (Continued)

\begin{tabular}{llrr}
\hline & $\$ 40,001$ to $\$ 60,000$ & 231 & 12.0 \\
& $\$ 60,001$ to $\$ 80,000$ & 248 & 12.8 \\
& Over $\$ 80,000$ & 596 & 30.8 \\
& Not stated & 303 & 15.7 \\
\hline Ownership of dwelling & Owned or being purchased & 1653 & 85.5 \\
& by the occupant & & 3.0 \\
& Rented from Housing Trust & 58 & 8.7 \\
& Rented privately & 168 & 1.4 \\
& Retirement village & 27 & 1.1 \\
& Other & 22 & 0.3 \\
\hline Pension or benefit & Refused & 5 & 37.9 \\
& Yes & 732 & 62.1 \\
\hline Total & No & 1201 & 100.0 \\
\hline Aboriginal or & & 1933 & 1.0 \\
Torres Strait Islander* & Aboriginal and/or & 15 & \\
& Torres Strait Islander & & 98.9 \\
Notal & No & 1482 & 0.1 \\
\hline Refused & 2 & 100.0 \\
\hline
\end{tabular}

*Only asked of those born in Australia.

close to ideal" and item 3 (Q2 Diener scale) "Have excellent life conditions" all had factor loadings of $>0.7$. Item 4 (Q4 Diener scale) "I have the important things in life" and item 5 (Q3 Environmental Mastery) "Able to create a lifestyle to my liking" both had factor loadings $>0.6$. Item 6 (Q4 Environmental Mastery) "In charge of living situation" and item 7 (Q5 Diener scale) "If I could live my life over I would change almost nothing" had loadings of $>0.5$. Item 8 (Q2 Environmental Mastery) "Difficulty arranging my life" and item 9 (Q5 Environmental Mastery) "Demands of life often get me down" had loadings of $>0.4$. These last two items also have loadings on component 2 (although values are lower than those on component 1 ).

Component 2 explained $16.7 \%$ of the variance. Item 10 (Q2 Positive Relations) "Most people have more friends than me", item 11 (Q1 Positive Relations) "Feel lonely because have few close friends", item 12 (Q5 Positive Relations) "Not experienced warm and trusting relationships, and item 13 (Q4 Positive Relations) "Maintaining close relationships has been difficult" all had factor loadings $>0.7$. Component 3 explained 9.7\% of the variance. Item 14 (Q3 Positive Relations) "People describe me as a giving

Table 2 Test scores and internal reliabilities of measures of psychological well-being and distress and their inter-correlations

\begin{tabular}{lcccccc}
\hline Scale & $\begin{array}{c}\text { Mean (SD) } \\
\text { \& range }\end{array}$ & $\begin{array}{c}\text { Alpha coeff of } \\
\text { internal reliability }\end{array}$ & $\begin{array}{c}\text { Pearson } \\
\text { correlations EM }\end{array}$ & PR & $\begin{array}{c}\text { Overall } \\
\text { well-being }\end{array}$ & K-10 \\
\hline Diener SWLS $n=1908$ & $26.3(5.7) 5-35$ & 0.80 & 0.62 & 0.47 & 0.90 & -0.47 \\
Ryff EM $n=1915$ & $19.5(2.8) 7-25$ & 0.73 & - & 0.52 & 0.81 & -0.55 \\
Ryff PR $n=1882$ & $24.0(3.4) 10-30$ & 0.74 & & - & 0.75 & -0.43 \\
Overall wellbeing & $69.9(9.9) 28-90$ & 0.86 & & & - & -0.56 \\
$n=1849$ & & & & & & - \\
K10 (PD) $n=1932$ & $15.4(5.6) 10-50$ & 0.85 & & & & \\
\hline
\end{tabular}


Table 3 Mean Overall well-being scores by demographic characteristics

\begin{tabular}{|c|c|c|c|c|}
\hline & $\mathrm{n}$ & Mean & SD & $95 \% \mathrm{Cl}$ \\
\hline \multicolumn{5}{|l|}{ Sex } \\
\hline Male & 895 & 69.6 & 9.7 & $69.0-70.3$ \\
\hline Female & 954 & 70.2 & 10.2 & $69.6-70.9$ \\
\hline \multicolumn{5}{|l|}{ Age group } \\
\hline 18 to 24 years & 227 & 69.4 & 8.3 & $68.4-70.5$ \\
\hline 25 to 34 years & 300 & 69.3 & 10.3 & $68.2-70.5$ \\
\hline 35 to 44 years & 356 & 70.5 & 10.3 & $69.4-71.5$ \\
\hline 45 to 54 years & 339 & 69.3 & 10.8 & $68.2-70.5$ \\
\hline 55 to 64 years & 279 & 71.2 & 10.5 & $69.9-72.4$ \\
\hline 65 to 74 years & 174 & 70.6 & 9.7 & $69.2-72.1$ \\
\hline 75 years and over & 174 & 69.1 & 8.4 & $67.8-70.3$ \\
\hline \multicolumn{5}{|l|}{ Number of adults in household } \\
\hline 1 adult & 277 & 66.5 & 11.4 & $65.2-68.0^{*}$ \\
\hline 2 adults & 1079 & 70.7 & 9.7 & $70.2-71.0^{*}$ \\
\hline 3 or more adults & 493 & 70.1 & 9.2 & $69.3-71.0^{*}$ \\
\hline \multicolumn{5}{|l|}{ Area of residence } \\
\hline Metropolitan & 1363 & 70.0 & 10.0 & $69.5-71.0$ \\
\hline Regional & 486 & 69.8 & 10.0 & $68.9-71.0$ \\
\hline \multicolumn{5}{|l|}{ Children in household } \\
\hline No children & 1137 & 69.5 & 10.1 & $68.9-70.0^{*}$ \\
\hline Children & 711 & 70.7 & 9.8 & $70.0-71.0^{*}$ \\
\hline \multicolumn{5}{|l|}{ Country of birth } \\
\hline Australia & 1442 & 69.8 & 10.1 & $69.3-70.0$ \\
\hline England/Ireland & 183 & 70.3 & 10.9 & $68.7-72.0$ \\
\hline Other & 224 & 70.4 & 8.5 & $69.2-71.0$ \\
\hline \multicolumn{5}{|l|}{ Language spoken at home } \\
\hline English & 1780 & 70.1 & 10.0 & $69.6-71.0^{*}$ \\
\hline Other & 68 & 65.8 & 8.5 & $63.8-68.0^{*}$ \\
\hline \multicolumn{5}{|l|}{ Marital status } \\
\hline Married/de facto & 1231 & 71.1 & 9.6 & $70.6-71.7^{*}$ \\
\hline Separated/divorced & 140 & 65.1 & 11.9 & $63.1-67.0^{*}$ \\
\hline Widowed & 111 & 68.0 & 9.7 & $66.2-69.8^{*}$ \\
\hline Never married & 366 & 68.4 & 9.7 & $67.4-69.4^{*}$ \\
\hline \multicolumn{5}{|l|}{ Education } \\
\hline Secondary & 842 & 68.9 & 10.1 & $68.3-70.0^{*}$ \\
\hline Trade/Certificate & 592 & 70.1 & 9.8 & $69.3-71.0^{*}$ \\
\hline Bachelor degree or higher & 415 & 71.7 & 9.8 & $70.8-73.0^{*}$ \\
\hline \multicolumn{5}{|l|}{ Work status } \\
\hline Full time employed & 738 & 71.0 & 9.4 & $70.3-72.0^{*}$ \\
\hline Part time/casual employment & 436 & 70.2 & 9.4 & $69.3-71.0^{*}$ \\
\hline Unemployed & 39 & 63.3 & 11.5 & $59.6-67.0^{*}$ \\
\hline Home duties & 111 & 68.3 & 11.2 & $66.2-70.0^{*}$ \\
\hline Retired & 387 & 70.3 & 9.3 & $69.4-71.0^{*}$ \\
\hline Student & 55 & 71.4 & 9.1 & $69.0-74.0^{*}$ \\
\hline
\end{tabular}


Table 3 Mean Overall well-being scores by demographic characteristics (Continued)

\begin{tabular}{|c|c|c|c|c|}
\hline $\begin{array}{l}\text { Unable to work because of } \\
\text { disability/Workcover/invalid }\end{array}$ & 54 & 57.4 & 12.4 & $54.0-61.0^{*}$ \\
\hline Other & 24 & 68.7 & 12.8 & $63.3-74.0^{*}$ \\
\hline Refused & 5 & 77.0 & 4.7 & $71.5-82.0^{*}$ \\
\hline \multicolumn{5}{|l|}{ Income } \\
\hline Up to $\$ 20,000$ & 229 & 66.7 & 11.9 & $65.2-68.0^{*}$ \\
\hline$\$ 20,001$ to $\$ 40,000$ & 287 & 68.3 & 10.0 & $67.2-70.0^{*}$ \\
\hline$\$ 40,001$ to $\$ 60,000$ & 221 & 68.6 & 10.4 & $67.3-70.0^{*}$ \\
\hline$\$ 60,001$ to $\$ 80,000$ & 244 & 70.8 & 9.4 & $69.6-72.0^{*}$ \\
\hline Over $\$ 80,000$ & 589 & 72.1 & 8.7 & $71.4-73.0^{*}$ \\
\hline Not stated & 287 & 69.9 & 9.8 & $68.7-71.0^{*}$ \\
\hline \multicolumn{5}{|l|}{ Dwelling } \\
\hline Owned or being purchased & 1585 & 70.5 & 9.6 & $70.1-71.0^{*}$ \\
\hline Rent from Housing Trust & 53 & 65.2 & 12.5 & $61.7-68.6^{*}$ \\
\hline Rented privately & 162 & 66.0 & 11.9 & $64.2-67.9^{*}$ \\
\hline Retirement village & 24 & 66.2 & 10.9 & $61.6-70.8$ \\
\hline Other & 20 & 68.8 & 6.8 & $65.6-72.0$ \\
\hline Refused & 5 & 73.9 & 6.4 & $65.5-82.2$ \\
\hline \multicolumn{5}{|l|}{ Pension status } \\
\hline No & 1175 & 70.7 & 9.4 & $70.1-71.2^{*}$ \\
\hline Yes & 674 & 68.6 & 10.7 & $67.8-69.4^{*}$ \\
\hline \multicolumn{5}{|c|}{${\text { Aboriginal or Torres Strait Islander } \wedge^{\dagger}}^{\dagger}$} \\
\hline No & 1428 & 69.8 & 10.1 & $69.3-70.3$ \\
\hline Yes & 12 & 69.5 & 4.8 & $66.9-72.5$ \\
\hline
\end{tabular}

Note: The weighting of the data can result in rounding discrepancies or totals not adding.

* Mean difference is significant at $p<.05$, assessed using $t$-test and Anova, post-hoc testing using the Scheffe test.

$\wedge$ Don't know/refused category not included.

†Aboriginal and Torres Strait Islander status only asked of those born in Australia.

person", item 15 (Q6 Positive Relations) "Enjoy personal and mutual conversation" and item 16 (Q1 Environmental mastery) "Good at managing life responsibilities" had factor loadings of $>0.6$. This last item also has a loading on component 1 (with a lower value) as does item 6 (Q4 Environmental Mastery) "In charge of living situation" (but with a higher value on component 1$)$.

Interpreting the factor analysis, it is apparent that the rotated component 1 accounts for the highest proportion of variance. Examining the items with the highest loadings this factor seems to be representing the concept of life satisfaction. Component 2 is for the most part examining negative personal relations, and component 3 could be labelled positive personal relations, although it had fewer than four items uniquely loading on it.

\section{Relations between PW and PD and sociodemographic variables}

Table 3 presents significant differences in the mean Overall well-being scores according to the demographic characteristics of respondents. Significant differences in mean values existed between categories for all demographic characteristics except for sex, age group, area of residence and Aboriginal or Torres Strait Islander status. 
Table 4 Summary of demographic characteristics associated with all scales

\begin{tabular}{|c|c|c|c|c|c|}
\hline & $\begin{array}{c}\text { Ryff } \\
\text { positive relations }\end{array}$ & $\begin{array}{c}\text { Ryff } \\
\text { environmental } \\
\text { mastery }\end{array}$ & Diener SWLS & $\begin{array}{c}\text { Overall } \\
\text { well-being }\end{array}$ & K10 \\
\hline Sex & $t=-3.14, p=0.002$ & $t=0.28, p=0.78$ & $t=0.02, p=0.99$ & $t=-1.28, p=0.20$ & $t=-4.28, p<0.001$ \\
\hline Age & $F=3.04, p=0.006$ & $F=4.43, p=0.001$ & $F=1.30, p=0.25$ & $F=1.74, p=0.11$ & $F=1.53, p=0.17$ \\
\hline $\begin{array}{l}\text { Household } \\
\text { size }\end{array}$ & $F=20.73, p<0.001$ & $F=2.76, p=0.06$ & $F=21.54, p<0.001$ & $F=20.21, p<0.001$ & $F=5.51, p=0.004$ \\
\hline $\begin{array}{l}\text { Area of } \\
\text { residence }\end{array}$ & $t=2.48, p=0.01$ & $t=-0.28, p=0.78$ & $t=-0.47, p=0.64$ & $t=0.42, p=0.46$ & $t=-1.73, p=0.08$ \\
\hline $\begin{array}{l}\text { Number of } \\
\text { children }\end{array}$ & $\mathrm{t}=-2.54, \mathrm{p}=0.01$ & $t=1.34, p=0.18$ & $t=-3.83, p<0.001$ & $\mathrm{t}=-2.62$ & $t=-0.37, p=0.71$ \\
\hline $\begin{array}{l}\text { Country of } \\
\text { birth }\end{array}$ & $F=0.30, p=0.74$ & $F=1.53, p=0.22$ & $F=0.52, p=0.59$ & $F=0.45, p=0.64$ & $F=0.15, p=0.86$ \\
\hline $\begin{array}{l}\text { Language } \\
\text { spoken }\end{array}$ & $t=5.61, p<0.001$ & $t=3.04, p=0.002$ & $\mathrm{t}=1.82, \mathrm{p}=0.07$ & $t=3.51, p<0.001$ & $t=-2.37, p=0.02$ \\
\hline $\begin{array}{l}\text { Marital } \\
\text { status }\end{array}$ & $F=12.42, p<0.001$ & $F=4.13, p=0.006$ & $F=33.08, p<0.001$ & $F=21.98, p<0.0$ & $F=5.94, p<0.001$ \\
\hline Education & $F=21.84, p<0.001$ & $F=4.78, p=0.008$ & $F=3.46, p=0.03$ & $F=10.92, p<0.001$ & $F=8.01, p<0.001$ \\
\hline Work status & $F=11.50, p<0.001$ & $F=13.43, p<0.001$ & $F=15.15, p<0.001$ & $F=15.71, p<0.001$ & $F=20.63, p<0.001$ \\
\hline Income & $F=18.50, p<0.001$ & $F=6.07, p<0.001$ & $F=9.00, p<0.001$ & $F=12.26, p<0.001$ & $F=10.98, p<0.001$ \\
\hline $\begin{array}{l}\text { Dwelling } \\
\text { ownership }\end{array}$ & $F=6.68, p<0.001$ & $F=7.07, p<0.001$ & $F=8.14 p<0.001$ & $F=9.68, p<0.001$ & $F=7.40, p<0.001$ \\
\hline $\begin{array}{l}\text { Aboriginal } \\
\text { Torres Strait } \\
\text { Islander }\end{array}$ & $t=2.14, p=0.03$ & $t=1.67, p=0.12$ & $t=-2.24, p=0.04$ & $t=0.09, p=0.93$ & $t=-1.27, p=0.23$ \\
\hline Pension & $\mathrm{t}=6.42, \mathrm{p}<0.001$ & $t=3.18, p=0.002$ & $t=2.57, p=0.01$ & $t=4.30, p<0.001$ & $t=-5.05, p<0.001$ \\
\hline
\end{tabular}

Table 4 summarises the demographic variables that were significantly associated with all of the scales. Marital status, work status, income and dwelling ownership were all characteristics significantly associated with all five scores.

Generally, variables with high mean scores for distress had low mean scores for wellbeing and vice versa, but there were two exceptions to this. Firstly, there was usually no significant difference in mean score between genders for the PW scales, but female gender was associated with higher scores of PD. Secondly living in a household with one or more children was significantly associated with higher scores for PW but there were no significant differences in mean scores for PD.

\section{Discussion}

The paper reports on a collection of 16 items from existing scales which as a total, captures the main dimensions of what the literature indicates as a consensus regarding the nature of psychological well-being: a sense of control, supportive social relations, and general satisfaction with life. The separate and the composite measures of PW are internally reliable, reasonably well correlated with each other, and negatively correlated with PD as expected.

The results indicate that if researchers wanted a briefer measure the 9-item scale formed from the factor analysis first component might be suitable, and if an even briefer measure were needed, the 5-item SWLS seems to be the best. Whether individual scales or the composite total is preferable for use may depend on specific research 
questions. The separate scales are not so highly correlated amongst themselves (either different components of PW, or PW against PD), as to suggest that only one factor is being investigated. The findings do not provide strong support for the need to measure PW separately from PD. However if public acceptance of positively worded items were to prove higher, it may be necessary to modify expression of EM and PR items currently phrased negatively.

An important question remains about what range of scores may be of prime interest to researchers. Well-established measures of PD have cut-off points above which scores validly suggest the need for clinical assessment and intervention, for example "high PD" is approximately the top $10 \%$ of the range of scores on the K10. It is common to use cut-off points to describe proportions of the population who for example, are at risk of a bad outcome, are disabled in everyday life (e.g. employment), or who need extra services. The national mental health survey in Australia established strong links between mental disorders such as anxiety and depression and the likelihood of being disabled in carrying out usual activities (Andrews et al. 2001; Dear et al. 2002). But what cut-off scores are meaningful in discussing well-being? Are researchers and public health policy-makers going to be interested only in the top $10 \%$ of $\mathrm{PW}$, or, as seems more likely, will they want to know about the sociodemographic and personal attributes of scorers in the top quartile or tertile? Keyes (2005) used tertiles and diagnoses modelled on the DSM-IIIR approach to distinguish those "flourishing" with complete mental health, from those "languishing", whose mental health places them between "moderately" well and those with mental illness. Huppert (2009) used these categories to advance the public health argument that shifting the average of the mental health distribution, even by a small change in score, would greatly increase the proportion of flourishing and decrease the languishing or mentally ill. Suggestions about how to achieve this small shift, such as schoolbased or worksite interventions (Huppert 2009) or more psychotherapy (Lamers et al. 2011) need to be seen in the context of more comprehensive prescriptions for mental health promotion (e.g. Herrman 2001).

\section{Suggestions for future research}

Further exploration of the applicability and predictive validity of the Overall well-being measure seems warranted, and comparisons with others such as the MHC-SF (Lamers et al. 2011) and the Warwick-Edinburgh Mental Well-being Scale (Tennant et al. 2007), are needed to evaluate the relative merits of different instruments.

Predictors of PW need to be explored further, and candidates would include both social determinants of health such as socio-economic status, and personal history factors such as parental rearing conditions and current satisfaction with social support. As a specific example, it would be extremely useful to gain insights into how parent attitudes to their children's achievements and failures in various areas of life, contribute to PW and resilience of those individuals in later life. Developmental changes with age also need more exploration. McMahan and Estes (2011) found that younger compared with older adults emphasised the experience of pleasure and self-development in their conceptions of well-being, while older people emphasised avoidance of negative experience more than younger ones, and there was no age difference in emphasis on making a contribution to others/making the world a better place. Westerhof and Keyes (2010) 
concluded that although older adults have fewer mental health problems than do younger adults, they are not in better positive mental health.

The longitudinal consequences of PW can be hypothesised as improved quality of life and life expectancy, less frequent use of health services, and adaptive coping with a range of adverse events such as acute and chronic illness and disability, relationship disruptions, single parenthood, work stress and unemployment. In fact researchers could learn more about "resilience", by closer study of individuals who score high on PW despite living in what we know to be adverse circumstances, such as being unemployed, living alone, or having low education. Such studies are likely to require indepth data collection in the form of interviews in order to enrich the scope of possible conclusions, by avoiding imposing preconceived ideas in the form of researcherselected questions.

Regarding the relationship between PW and PD, numerous researchers have argued for the independence of positive and negative affect (e.g. Larsen et al. 2001; Warr et al. 1983), but Huppert's (2009) review concluded that well-being and ill-being have many common drivers. Keyes and colleagues (Keyes 2005; Lamers et al. 2011) have concluded there are separate but correlated axes of mental health and mental illness. The answer is unlikely to be categorical. For example Zautra et al. (2005) proposed that in times of low stress, positive and negative affect are relatively uncorrelated, but that in stressful situations they collapse to a simpler bipolar dimension. And McNulty and Fincham (2012) have recently shown that whether forgiveness, optimism, benevolent attributions and kindness have positive outcomes or not depends on the interpersonal context; this contextual dependence means that "Just as studying dysfunction cannot tell researchers how to promote flourishing .... studying flourishing cannot tell us how to prevent suffering" (p.107). Therefore the extent to which PW and PD are independent of each other may vary according to the external and internal environmental challenges people face, and researchers will need to make choices about the value of measuring both, according to those considerations.

\section{Conclusions}

The total of 16 items from exisiting scales to measure well-being shows psychometric promise for community surveys, and shorter versions have here been recommended according to researcher needs. In a representative community sample of adults, psychological well-being and psychological distress were driven by very similar sociodemographic characteristics

The issue of appropriate cut-off scores needs further investigation, to determine if there are categories of relative PW which predict successful coping with serious stress, illness or adversity. There might for example be high utility in a measure of PW where scores within a given range could reliably predict benefits from interventions such as better education, psychoeducation, or access to health care. 


\section{Acknowledgements}

This study was funded as part of the Assessment of the Determinants and Epidemiology of Psychological Distress (ADEPD) study, through the Strategic Health Research Program 2007 - 2009, SA Health.

\section{Author details}

${ }^{1}$ School of Psychology \& Discipline of Psychiatry, University of Adelaide, Adelaide, South Australia 5005, Australia. ${ }^{2}$ Population Research and Outcome Studies, Discipline of Medicine, The University of Adelaide, Adelaide, South Australia, Australia.

Received: 31 January 2012 Accepted: 14 June 2012

Published: 25 June 2012

\section{References}

Andrews, G., Henderson, S., \& Hall, W. (2001). Prevalence, comorbidity, disability and service utilization: Overview of the Australian National Mental Health Survey. British Journal of Psychiatry, 178, 145-153. doi:10.1192/bjp. 178.2.145

Australia Bureau of Statistics. (2007). 3235.0 Population by Age and Sex, South Australia, 30 June 2007. Canberra: Australian Bureau of Statistics.

Australian Bureau of Statistics. (2001). 4817.0.55.001 Information Paper: Use of the Kessler Psychological Distress Scale in ABS Health Surveys. Canberra: Australian Bureau of Statistics.

Beck, L. (2007). Social status, social support, and stress: A comparative review of the health consequences of social control factors. Health Psychology Review, 1, 186-207.

Berkman, L., \& Breslow, L. (1983). Health and ways of living. New York: Oxford Press.

Boehm, J. K., Peterson, C., Kivimaki, M., \& Kubzansky, L. (2011). A prospective study of positive psychological well-being and coronary heart disease. Health Psychology, 30, 259-267. doi:10.1037/a0023124

Cohen, S., \& Lemay, E. P. (2007). Why would social networks be linked to affect and health practices? Health Psychology, 26, 410-417. doi:10.1037/0278-6133.26.4.410

Dear, K., Henderson, S., \& Corten, A. (2002). Well-being in Australia: Findings from the national survey of mental health and well-being. Social Psychiatry and Psychiatric Epidemiology, 37, 503-509. doi:10.1007/s00127-002-0590-3

Deci, E. L., \& Ryan, R. M. (2008). Hedonia, eudaimonia, and well-being: An introduction. Journal of Happiness Studies, 9, 1-11. doi:10.1007/s10902-006-9018-1

Diener, E., Emmons, R. A., Larson, R. J., \& Griffin, S. (1985). The satisfaction with life scale. Journal of Personality Assessment, 49, 71-75. doi:10.1207/s15327752jpa4901_13

Diener, E., Scollon, C. K. N., Oishi, S., Dzokoto, V., \& Suh, E. M. (2000). Positivity and the construction of life satisfaction judgements: Global happiness is not the sum of its parts. Journal of Happiness Studies, 1, 159-176.

Diener, E., Oishi, S., \& Lucas, R. E. (2003). Personality, culture, and subjective wellbeing: Emotional and cognitive evaluations of life. Annual Review of Psychology, 54, 403-425. doi:10.1146/annurev.psych.54.101601.145056

Foresight Mental Capital and Wellbeing Project. (2008). Mental Capital and Wellbeing: Making the most of ourselves in the $21^{\text {st }}$ century - Executive Summary. London: Government Office for Science.

Freidli, L. (2009). Mental health, resilience and inequalities. Copenhagen: World Health Organisation Europe.

Herrman, H. (2001). The need for mental health promotion. Australian and New Zealand Journal of Psychiatry, 35, 709-715.

Holt-Lunstad, J., Smith, T. B., \& Layton, J. B. (2010). Social relationships and mortality risk: A meta-analytic review. PLoS Medicine, 7, e1000316.

Huppert, F. A. (2009). Psychological well-being: Evidence regarding its causes and consequences. Applied Psychology: Health and Well-Being, 1, 137-164. doi:10.1111/j.1758-0854.2009.01008.x

Kessler, R. C., Andrews, G., Colpe, L. J., Hiripi, E., Mroczek, D. K., Normand, S. L. T., Walters, E. E., \& Zaslavsky, A. M. (2002). Short screening scales to monitor population prevalences and trends in non-specific psychological distress. Psychological Medicine, 32, 959-976. doi:10.1017/50033291702006074

Keyes, C. L. M. (2005). Mental illness and/or mental health? Investigating axioms of the complete state model of mental health. Journal of Consulting and Clinical Psychology, 73, 539-548. doi:10.1037/0022-006X.73.3.539

Keyes, C. L. M., Wissing, M., Potgieter, J. P., Temane, M., Kruger, A., \& van Rooy, S. (2008). Evaluation of the mental health continuum-short form (MHC-SF) in Setswana-speaking South Africans. Clinical Psychology \& Psychotherapy, 15, 181-192.

Lahey, B. B. (2009). Public health significance of neuroticism. American Psychologist, 64, 241-256. doi:10.1037/a0015309

Lamers, S. M. A., Westerhof, G. J., Bohlmeijer, E. T., ten Klooster, P. M., \& Keyes, C. L. M. (2011). Evaluating the psychometric properties of the Mental Health Continuum-Short Form (MHC-SF). Journal of Clinical Psychology, 67, 99-110. doi:10.1002/jclp. 20741

Larsen, J. T., McGraw, A. P., \& Cacioppo, J. T. (2001). Can people feel happy and sad at the same time? Journal of Personality and Social Psychology, 81, 684-696. doi:10.1037//0022-3514.81.4.684

Lucas, R. E., Diener, E., \& Suh, E. (1996). Discriminant validity of wellbeing measures. Journal of Personality and Social Psychology, 71, 616-628.

MacMahan, E. A., \& Estes, D. (2011). Age-related differences in lay conceptions of well-being and experienced wellbeing. Journal of Happiness Studies, doi:10.1007/s10902-2111-9251-0 published online 15 February 2011.

Manning, M., \& Munro, D. (2007). The Survey Researcher's SPSS Cookbook (2nd ed.). Sydney: Pearson Education.

McNulty, J. K., \& Fincham, F. D. (2012). Beyond positive psychology? Toward a contextual view of psychological processes and well-being. American Psychologist, 67, 101-110. doi:10.1037/a0024572

Ryff, C. D. (1989). Happiness is everything, or is it? Explorations on the meaning of psychological well-being. Journal of Personality and Social Psychology, 57, 1069-1081. doi:10.1037//0022-3514.57.6.1069

Ryff, C. D., \& Singer, B. (1996). Psychological well-being: Meaning, measurement, and implications for psychotherapy research. Psychotherapy and Psychosomatics, 65, 14-23. 
Tennant, R., Hiller, L., Fishwick, R., Platt, S., Joseph, S., Weich, S., Parkinson, J., Secker, J., \& Stewart-Brown, S. (2007). The Warwick-Edinburgh Mental Well-being Scale (WEMWBS): development and UK validation. Health and Quality of Life Outcomes, 5, 63-75. doi:10.1186/1477-7525-5-63

Warr, P., Barter, J., \& Brownbridge, B. (1983). On the independence of positive and negative affect. Journal of Personality and Social Psychology, 44, 644-651. doi:10.1037//0022-3514.44.3.644

Westerhof, G. J. \& Keyes, C. L. M. (2010). Mental illness and mental health: The two continua model across the lifespan. Journal of Adult Development, 17, 110-119. doi:10.1007/s10804-009-9082-y

$\mathrm{Xu}, \mathrm{J}$., \& Roberts, R. E. (2010). The power of positive emotions: It's a matter of life or death - Subjective well-being and longevity over 28 years in a general population. Health Psychology, 29, 9-19. doi:10.1037/a0016767

Zautra, A. J., Affleck, G. G., Tennen, H., Reich, J., \& Davis, M. C. (2005). Dynamic approaches to emotions and stress in everyday life: Bolger and Zuckerman reloaded with positive as well as negative affects. Journal of Personality, 73, 1511-1538. doi:10.1111/j.1467-6494.2005.00357.x

doi:10.1186/2211-1522-2-3

Cite this article as: Winefield et al: Psychological well-being and psychological distress: is it necessary to measure both? Psychology of Well-Being: Theory, Research and Practice 2012 2:3.

\section{Submit your manuscript to a SpringerOpen ${ }^{\circ}$ journal and benefit from:}

- Convenient online submission

- Rigorous peer review

- Immediate publication on acceptance

- Open access: articles freely available online

- High visibility within the field

- Retaining the copyright to your article

Submit your next manuscript at $\gg$ springeropen.com 